\title{
Documentação Profissionalizada
}

\author{
FENELON Silva
}

FORMAÇÃO, SELEÇÃO E APERFEIÇOAMENTO DO DOCUMENTARISTA

$\mathrm{O}$

ENSINo da Documentação começou, de maneira formal, com MelviL Dewey, na biblioteca do Amhrest College de Massachussets, em 1873.

Por largos anos o ensino da Biblioteconomia foi ministrado por métodos puran.ente tecnológicos em quase tôdas as bibliotecas importantes dos Estados Unidos, inclusive pela New York Public Library; constituia essa aprendizagem apenas de rotinas de serviços técnicos.

No fim do século houve um movimento que eliminou êste tipo de treinamento e novos métodos foram adotados nas Universidade de Colúmbia, Illinois e Western Reserve.

No conêço dêste século. Williamson bateu-se pela idéia de que a classe avulsa de treinamento de bibliotecários deveria ser abolida e no seu lugar, escolas profissionais de biblioteconomia deveriam ser criadas nas próprias universidades. WiLliamson foi o primeiro deão da Escola de Biblioteconomia da Columbia University, e em 1926, os graduados dessa Escola recebiam o titulo de bachelor of science e o major degree. quer dizer, bachelor's degree in libraty science.

BRETT, da biblioteca pública de Cleveiand, que também procurou filiar os bibliotecários à universidade, foi o primeiro reitor da Escola de Biblioteconomia de Western Reserve University.

A mudança elevou o nivel de ensino de puramente técnico para o conhecimento mais amplo de outras disciplinas e, conseqüentemente, a profissão ganhou novo prestígio.

Por volta de 1930 a Carnegie Corporation doou um fundo à Universidade de Chicago para o estabelecimento de uma escola de biblioteconomia mais adiantada, que conferisse o master degree e o grau de Philosophy Doctor; isso determinou um estudo da carreira de bibliotecário, com o fim de se fixarem quais as disciplinas que deveriam ser estudadas num curso superior de biblioteconomia.

Estudando profundamento o problema, WILson, em 1932, chegou à conclusão de que a biblioteca é uma instituição social e, portanto, os bibliotecários deviam ter uma base sólida em ciências sociais, donde ter conse- 
guido auxilio financeiro da Carnegie Corporation para a instituição de bôlsas de escudos para um grupo selecionado de bibliotecários.

Ainda hoje, muitos ex alunos da Graduate Library Scholl do tempo de WILSON, encontram-se espalhados pelos Estados Unidos e quase todos ocupando funções de destaque.

$\mathrm{Na}$ Europa, cursos esparsos vêm sendo feitos desde 1895 quando, em Bruxelas, na Conferência Internacional de Bibliografia, criou-se o Instituto Internacional de Bibliografia, mais tarde transformada em Federação Internacional de Documentação, até que em 1948/49, a Union Française des Organismes de Documentation fêz realizar uma série dos melhores cursos técnicos de Documentação até hoje dados em qualquer parte do mundo.

Constituiu o programa dêsses cursos das seguintes disciplinas:

I - Documentação e documentologia (Suzanne Briet e Louis Mestre).

II - Documentos: categorias, pesquisas, seleção, coleta (Lours Boulonnois, M. E. de Grolier e L. N. Malcles).

III - Conservação - Classificação - Catalogação (REnÉ GANDILHon, M. H. Clavier, M. E. de Grol.ier, René Dubuc, Suzanne Briet, M. Chabrier, M. J. Bruno e C. Meufret).

IV - Biblioteconomia - Arquivista - Museografia (André Martin, M. Chabrier, M. G. Bourgin, M. F. Boucher, M. F. Bourdier e Jean PRINET).

$\mathrm{V}$ - Equipamento e instrumental documentário (PAuL. PoIndron, Maurich Borgeaud, De Trienda e Louis Mestre).

VI - Elaboração de trabalhos documentários (EDouard VIncent, O. Bastien e A. Lattes).

VII - Meios de expressão e de difusão da Documentação (M. Rossignol, Robert Brun, J. Adhemar, Louis Mestre, Mlle. Salomé e P. JOSSERAND).

VIII - Organização e administração (JEAn Dubas).

IX - Usuários e técnicos da Documentação (H. Marty).

No Brasil, a primeira tentativa no sentido de se dar organização ao ensino da Biblioteconomia data de 1911, quando pelo Decreto nò 8.835, de 11 de julhe daquele ano que aprovava o Regulamento da Biblioteca Nacional, criava-se o Curso de Biblioteconomia com as seguintes disciplinas:
a) Bibliografia;
b) Paleografia;
c) Diplomacia;
d) Iconografia;
e) Numismática. 
Em 1922 (Decreto $\mathrm{n}^{\circ}$ 15.670, de 6 de setembro),

"o curso técnico, destinado a habilitar os candidatos ao cargo de de amanuense da Biblioteca Nacional e do Arquivo Nacional e ao de $3^{\circ}$ oficial do Museu Histórico Nacional"

passou a constar das seguintes matérias:

Primeiro ano - I. História literária (com aplicação à Bibliografia); II. Iconografia; III. Cartografia (estudo, descrição e catalogação das cartas geográficas).

Segundo ano - I. Bibliografia; II. Paleografia; III. Diplomática.

Com o advento do Decreto $n^{\circ} 6.440$, de 27 de abril de 1944, foi dada nova organização ao Curso que ficou assim estruturado:

a) Curso Fundamental de Biblioteconomia;

b) Curso Superior de Biblioteconomia;

c) Cursos Avulsos.

Nesse mesmo ano, ferevereiro de 1944 , o D.A.S.P. fazia realizar nos Cursos de Administração, um curso extraordinário de Documentação, o primeiro, certamente, a se ministrar no Brasil.

A rêde de centros (bibliotecas especializadas), serviços, organismos de Documentação começou a se formar em 1940 quando se criou e organizou o Serviço de Documentação do D.A.S.P. (Decreto-lei $n^{\circ} 2.03$ ), de 27 de fevereiro); nesse mesmo ano, 29-2-40, criava-se o Serviço de Documentação do Ministério da Educação; em 1942, 30 de junho, o do Ministério das Relações Exteriores; em 1943; 5 de novembro, o do Ministério da Justiça; em 1944, 17 de abril, o da Viação, 21 de outubro, o da Agricultura e 27 de outubro, o do Trabalho; em 1953, com a Lei $\mathrm{n}^{\circ} 1.920$, de 25 de julho, criava-se, afinal, o Serviço de Documentação do Ministério da Saúde.

O I.B.B.D., Instituto Brasileiro de Bibliografia e Documentação, que tem sua origem na Lei $\mathrm{n}^{9} 1.310$, de 15 de janeiro de 1951 , que criou o Conselho Nacional de Pesquisas, organizou-se em bases as mais promissoras, com o Decreto $n^{2} 35.430$, de 29 de abril de 1954 .

Em 1957 o I.B.B.D. fêz realizar Cursos de Pesquisas Bibliográficas coni as seguinies cadeiras principais:

I - Documentação e Organização Bibliográfica (Jesse H. SulerA);

II - Técnica da Organização e da Pesquisa Bibliográfica (EDson NerY DA FONSECA);

III - Serviços Técnicos (Ada Maria Coaracy);

IV -- Catalogação e Classificação (LAIS DA BOA MORTE).

A profissionalização documentarista deve ter nascido no Brasil com a criação da séria funcional de Assistente de Documentação nos quadros do pessoal do D.A.S.P. em 1946 (Decreto $\mathrm{n}^{\circ} 21.500$, de 27 de julho). 
O primeiro concurso público (prova de habilitação) para a seleção de documentaristas (assistente de documentação), foi realizado pelo D.A.S.P. em 1948; nesse concurso exigia-se dos candidatos, conhecimentos de Português (nivel de dificuldade do curso ginasial completo), Direito Administrativo e Documentação, constando esta prova da resolução de questões objetivas e práticas sôbre assuntos do seguinte programa:

19) conceito e fins da Documentação;

29) partes da Documentação: a biblioteca, o arquivo, filmoteca e discoteca; coleções museográficas;

3.) o papel da Biblioteca na Documentação;

4\%) a biblioteca especializada - seu valor;

59) catalogação e classificação de livrç; sistemas mais usados;

6\%) o serviço de bibliografia e referência;

7०) a administração da biblioteca; serviço de empréstimo;

8) os diferentes tipos de arquivo; o arquivo vivo e o arquivo morto;

90) catalogação e classificação de documentos;

10\%) os órgãos da Documentação; a Biblioteca e seus diferentes tipos; o serviço de Documentação e a agência da publicidade;

11\%) tipos de responsabilidades da agência de publicidade;

12:) o relatório administrativo; fins mediatos e imediatos; tipos e modelos, técnica de preparação;

13) O relatório técnico ou profissional;

14) a divulgacão ao público - seus objetivos; o relatório criual de atividades; o relatório financeiro; a divulgação das leis;

15\%) instrumentos de divulgação: o rádio, o cinema, o jornal, as publicações, as exposições; vantagens e desvantagens de cada um:

16ः) métodos de impressão; mimeografia, ditografia, multiliggrafia e linotipia;

17\%) conhecimento sôbre técnica de publicidade; técnica de cartazes e letreiros; o fator atração ligado ao fato economia; aplicação de técnica da propaganda com objetivos da administração pública;

18. conteúdo do material de divulgação; tipos de apresentação; texto, tabelas estatísticas, gráficos e gravuras; cuidado quanto ao uso de tabelas e gráficos;

190) a distribuição ao público; escolha dos destinatários; condições de obtenção de material de divulgaçąo; público.

20:) critério para julgamento dos relatórios oficiais destinados ao 
Criou-se, ùltimamente, (1957), no I.N.I.C., Instituto Nacional de Imigração e Colonização, a carreira de Documentarista (5 classes, 24 cargos, padrões $\mathrm{I} / \mathrm{M})$, para cujo preenchimento cogita-se fazer realizar concurso público; dos candidatos exigem-se conhecimentos de Português (rivel de dificuldade da $3^{a}$ série ginasial), idioma estrangeiro, constante de tradução para o Português de um trecho de Inglês, Francês ou Alemão (à escolha, do candidato) e técnica de Documentação.

Também o Serviço Social Rural acaba de prevê (1958) a criação no seu quadro de 10 cargos isolados de Documentarista.

De alguma forma, a base cultural do documentarista deve abranger:

$1^{\circ)}$ Conhecimento geral de tôdas as disciplinas: sociologia, filosofia, história etc.;

2) Especialização em alguma dessas disciplinas;

3:) Conhecimento de Biblioteconomia, Arquivologia e Museologia e suas relações com outros ramos da ciência.

No estágio atual da Documentação, será de tôda a conveniência que nas universidades haja uma verdadeira união entre a Documentação e outros departamentos; já se conseguiu convencer os especialistas de outros assuntos da importância desta união através do intercâmbio e desenvolvimento de idéias e tudo indica que já se pode atingir a um ponto de real interêssse para os especialistas de cada assunto.

A Universidade de Chicago acaba de estabelecer um novo programa de ensino para a Escola de Biblioteconomia, a fim de conceder aos alunos que fizerem estudos avançados, o grau de philosophy doctor; o mesmo regime foi estabelecido na Western Reserve University.

Já é tempo de se estruturar, no Brasil, o Curso de Documentologia em nível universitário, que abranja cadeiras de Arquivologia, Iconografia, Museografia, Bibliologia, Filmografia e Relacionômica (relações públicas); e que, de início, êsse curso integre a Faculdade Nacional de Filosofia, da Universidade do Brasil. 